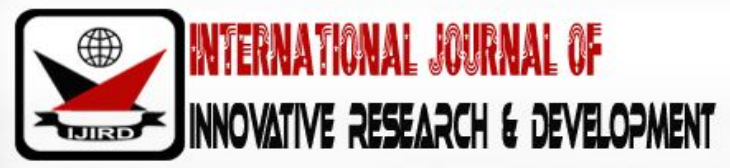

ISSN 2278 - 0211 (Online)

\section{Impacts of Environments on Employees Job Satisfactions and Performances in Public Services Sector in Ghana}

\author{
Abiel.A. Armah \\ Ph.D. Candidate, Accra Institute of Technology, Ghana
}

\begin{abstract}
The aim of the paper is to examine environmental factors affecting employees 'job satisfaction and performances in the public sector in Ghana. The objective of this paper is to examine key environmental factors of employees' job satisfactions and performances and subsequently establish the influence of environmental factors on employees' job satisfactions and performances in public sector in Ghana. The study focused on environmental dimensions such as working conditions, supervision, reward, co-worker, self -improvement and communication. Cross sectional survey was employed and simple random technique was used. A sample size of 150 employees was used. Data was analyzed using descriptive statistics analysis and multiple regressions. The results of the study showed that self- improvement, supervisions, and co-worker were environments factors that negatively influence employees' job satisfactions and performance on public sector. However, reward, communication and working conditions showed positive influence on employees' job satisfactions and performance on public sector.
\end{abstract}

Keywords: Environment, environmental factors, employee's job satisfaction and performances, public sector organizations

\section{Introduction}

Public organizations in Ghana face immense pressure to excel in their performances due to the highly unstable and competitive environment in which they operate. This environment is characterized by factors such as increased globalization, demanding stakeholders, shortage of critical skills, increased workforce diversity as well as technological innovations (Mayfield and Mayfield, 2002 cited in Mafini and Pooi 2013). These factors compel public sector organizations to develop and implement strategies for improving environments in which they operate. One such strategy is to have employees who are highly satisfied with their work (Okanya, 2007 cited in Mafini and Pooi (2013). This calls for organizations to place more emphasis on recognizing and enhancing all components of work linked to higher levels of employee satisfaction.

Most organizations usually adopt measures that focus on advanced technology and equipment, capital and other materials yet often pay little attention to the environment of the organization. Despite these technological advancements, most organizations face challenges with regards to improving environments in which they operate.

The public sector in Ghana is the largest employer of Ghanaians. It is also the sector that has witnessed many agitations from workers in recent times. These agitations which are mainly in the form of strikes have come about as a result of dissatisfaction of working conditions among employees in this sector and environment is not exceptional. While employees in the public sectors have, over the years, raised concerns about their working conditions, governments over the years have also tried in their effort to improve performance and satisfaction among workers in the public sector but still left to be desired. Most researchers have rather focused on salary as the only means to improve employees working conditions but there are other environmental factors accounted for employees' performance in public sectors in Ghana. However, since the implementation of this policy, there have been strikes and agitations among some public-sector workers especially in the health and education sector. The study seeks to assess the effect of environments on employees' performance in public sector institutions.

\subsection{Objectives}

- To examine key environmentalfactors on employees' performances.

- To establish the influence of environmental factors on employee's job performances in public sector in Ghana

\subsection{Hypothesis}

From the objectives, the study hypotheses are formulated as follows: 
- H1: There are environmental factors that influence the employees' performances in public sector

- H0: There are no environmental factors that influence the employees' performances in public sector

\section{Literature Review}

The chapter presents a review of literature on the effect of environments on employees' performance in public sector.

\subsection{Organizational Environment}

Camilleri (2012) examined the relationship between the organization and the employee, how they are formed and how they impact the employee's "behaviour, well-being and contributions to organizational effectiveness" (p. 357). He also suggested that the PSM of public employees is, in large part, the result of the organizational environment. Based on the literature and existing research, Camilleri (2012) suggested that the employee perception of the organization, relationship with the leader and specific job characteristics have a positive effect on PSM whereas conflict and ambiguity have a negative impact on PSM.

Camilleri (2012) conducted a cross sectional study of the survey responses of 3,400 public officers using Perry's (2012) scale to measure PSM. The survey also measured employee perception of the organization, employee-leader relations, job attributes and personal attributes. Camilleri (2012) found that a positive perception of the organization and job characteristics were positively related to employee PSM as was positive employee leader relationship. Age and gender were the personal attributes most strongly related to PSM. Although job tenure was found to have no effect ton PSM, organizational tenure had a negative relationship with PSM which is consistent with previous findings (Perry and Wise, 2012). Camilleri (2012) concluded that the PSM of public employees is most profoundly impacted by the organizational environment and suggested that providing employees with clear, prioritized goals maximizes PSM. Additionally, employee-leader relationships had a positive impact on PSM and these relationships can be strengthened or improved through shared decision making, clarifying ambiguity, and providing feedback. Employee perceptions of the organization had a direct positive impact on PSM; therefore, Camilleri encouraged managers to foster creativity, demonstrate confidence and trust focus on customers rather than production and remain flexible.

Moynihan and Pandey (2012) examined the work environment in relation to employee beliefs and the ways organizational influences shape PSM. The researchers contended that PSM may be shaped by an individual's social history such as religion, education and professional memberships as well as work-related procedures and standards that shape organizational behavior and attitudes of public employees toward public service (Moynihan and Pandey, 2012).

Moynihan and Pandey (2012) used a data set from the 2002/ 2004 NASP Phase II to examine employee perceptions of culture, hierarchy, red tape and reform as well as the effects of length of membership in the organization. The survey respondents $(\mathrm{n}=$ 274) reflected $53 \%$ of the population of information managers at state health and human-services agencies. The average age of the respondents, almost half of who were women, was 50years old and their average tenure with the organization was more than 15 years. The average respondent salary was $\$ 50,000$ to $\$ 75,000$. The survey included three of Perry's (2012) four dimensions of PSM: attraction to public policy-making, commitment to public interest and compassion but excluded selfsacrifice. Moynihan and Pandey (2012) derived the measure of culture-group, developmental, hierarchical and rationalfrom Zammuto and Krakower (2010) adapted for inclusion in NASP-II.

Results suggested the significance of the socio-historical context and offered support for the influence of the organization on the dimensions of PSM test (Moynihan and Pandey, 2012). Although the measures of culture used in the study did not prove significant, research findings suggested that the organization plays an important role in shaping PSM and active organizational reform efforts are positive and significant predictors of PSM. The findings also suggested the existence of bureaucracy reduces PSM as does the length of membership with the organization.

Jacobsen (2011) examined the organizational environment as it pertains to upwardly mobile, mid-level managers at two federal agencies to evaluate the role organizations play in fostering and developing the PSM of their employees and the extent to which PSM contributes to initial job selection by employees. He measured PSM using all four dimensions of Perry's (2012) scale as well as open-ended and semi-structured interviews to collect data from each respondent.

Jacobsen's (2012) research participants consisted of upper middle managers at the Internal Revenue Service (IRS) and the U.S. Patent and Trademark Office (USPTO) who were predominantly accountants, scientists and engineers. All participants were federal workers/ public servants in organizations characterized as performing nonsocial service functions. Additionally, all members of the sample were participants in executive training programs in their organizations. His research sample was not random in that upper middle managers at the IRS or USPTO did not have equal probability of being selected; the sample population of the study consisted of one USPTO and two IRS executive training classes chosen by the researcher. Jacobsen (2012) indicated that although the sampling was purposeful, participants varied in their levels of PSM, ideas of PSM, work experience and positions in their organizations. The PSM survey response rate was $92 \%$ for the USPTO $(n=35)$ and $67.4 \%$ for the IRS $(n=55)$. In addition to their survey participation, $44 \%$ of the USPTO and $60 \%$ of the IRS participants agreed to participate in the qualitative data collection.

Jacobsen (2012) found that research participants had high levels of PSM compared to individuals in other federal agencies and that the PSM of IRS respondents was higher than those of the USPTO except on the interest in policy-making 
scale. Although the sample population demonstrated high levels of PSM, public service was not found to be important in their initial job selection. PSM, however, was found to have developed over time with the organization and was a factor in both retention and performance (Jacobsen, 2012).

Jacobsen (2012) concluded that PSM can be developed by organizations for their current employees and that it may be valuable for organizations to market public service as a recruitment strategy although in the current economy it is reasonable to anticipate that economic reasons will remain the primary motivation for those seeking employment. Jacobsen (2012) recommended that organizations find ways to increase PSM in their current employees and suggested specific strategies for public sector human resource departments such as emphasizing the value of public service in their recruitment efforts or establishing mentoring programs to assist employees in discovering the public service benefits of their positions.

The organizational environment has a profound impact on PSM (Camilleri, 2012). Researchers demonstrated that clear goals, shared responsibility, opportunities for autonomy and creativity and a common mission and vision are organizational factors that play a role in shaping PSM. PSM can be developed by organizations (Jacobsen, 2011). PSM can be lessened or damaged over time if organizations fail to address employees' experiences with conflict or ambiguity (Camilleri, 2012) or are ineffective in articulating how jobs are connected to the organizational mission or cease to provide meaningful work that satisfies employees' intrinsic motivations (Perry and Lee, 2012 cited in Inmran, 2014).

\subsection{Environmental factors that affect Employees Job Satisfaction and Performances}

Environmental factors consist of working conditions, personal development opportunities, rewards, supervision, coworkers and communication. A brief summary are as follows:

\subsection{Working Conditions}

Working conditions consist of the physical and social conditions at work. People want to work in a comfortable, safe, clean, modern and well-equipped environment (Sun, 2013). They also prefer to work in good conditions within convivial and serene atmosphere (Green, 2012). For example, people can be disturbed when they are distracted by unexpected noise such as telephones, conversations or crowding (Bridger and Brusher, 2014) and absence of temperature or lighting causes strain (MacMillan, 2012).

\subsection{Self-Improvement}

Workers want to improve their skills, abilities, knowledge and also learn new things especially those which provide personal growth. In parallel, if they are satisfied on self-improvement opportunities, their overall job performances level increases. Therefore, job training plays a key role for personal development opportunities and helps employees to be more specific with their job. As a result, employee job satisfaction increases hence improved performances. In addition, employee development programmes improve workers' satisfaction level by giving them more sense of confidence, control over their career and increasing positive feelings towards their job (Jin and Lee, 2012).

\subsection{Reward}

According to Kalleberg (2012), reward is related with the employee's desire and it motivates employees. It shows what an employee wants after performing a certain task. According to Gerald and Dorothee (2013), rewards are very strongly correlated with job satisfaction (Javed et al., 2012). Moreover, according to the related literature, rewards are divided into two categories as; extrinsic rewards and intrinsic rewards. Extrinsic rewards consist of money, promotion and benefits. Intrinsic rewards include having a sense of achievement, being part of a team's success, being appreciated by superiors because of a good performance and feeling recognized. Job satisfaction increases with all these feelings and returns (Başar, 2012).

\subsection{Supervision}

Employee job satisfaction has positively been affected by supervisors' support and recognition of employees (Yang, et al., 2012). Since the supervisors are representatives for the institution, if they are supportive and helpful, employees perceive the organization as the same (Emhan, et al., 2014). Communication between supervisors and subordinates determine employees' attitudes towards their jobs. In addition, management style of supervisors is important and it can be different. For example, in one type, supervisors implement such things like checking to see employees' performance and communicating with subordinates. In another type, they allow their subordinates to participate in decisions related with their jobs (Yeltan, 2013, and Beșiktas, 2012). Moreover, lack of communication between employees and supervisors negatively affect employees' job performance.

\subsection{Co-worker}

Employees that have a better relationship with their co-workers are more likely to be satisfied with their job (Yang, et al., 2012). According to Locke, employees prefer to work with people being friendly, supportive, and cooperative (Başar, 2012). Since people spend majority of their time with colleagues, if co-workers make them happy, this has positive impact on their job satisfaction (Beşiktas, 2012) 


\subsection{Communication}

Communication within workplace is essential for organizations in terms of job satisfaction. According to Ozturk, Hancer et al. (2014), there are two different dimensions of internal communication in organizations. One of them is managerial communication such as giving oral presentation and giving feedback. The other one is informal interaction such as communication with each other beyond formal channels. Effective interaction and communication improve job satisfaction and performances. On the contrary, lack of communication causes dissatisfaction.

\section{Methodology}

This deals with the method adopted for the purpose of achieving the study objectives. The research design adopted for this study is the quantitative method. Quantitative research revolves around collecting numeric data, testing and confirming hypothesis formed on the basis of existing theory (Baxter and Jack 2008). The population for this study involved all public servants in Ghana. Employees of public sector organizations include the Civil Service, Ghana Health Service, Local Government Service, Polytechnics, sub vented agencies such as the Electoral Commission, National Commission for Civic Education, Commission for Human Rights and Administrative Justice (CHRAJ) and the Statistical Service. For the purpose of this research, simple random technique was utilized. A sample size of 150 employees was used for the study. This figure was considered to be quite representative to help arrive at a conclusion that could be acceptable. Survey research was used as the primary source of data collection supported by secondary data. The sampling frame to be used will be the list of employees to be obtained from the public services commission and the various public-sector organizations that will be included in the sample. Data was analyzed using descriptive statistics and multiple regressions.

\subsection{Regression Model}

A regression model in the form stated in equation 1 shall be used to establish the relationship between environments factors and employee job satisfactions and performance in public sectors.

\subsection{Dependent Variable}

The dependent variable used in this study is employee job satisfaction and performance.

\subsection{Independent Variable}

The independent variables are classified as environments factors.

$$
\text { yip }=\beta 0+\beta 1 \chi 1+\varepsilon j \text {. }
$$

Where:

yip =refers to as employee job satisfaction and performance

$\beta 1 \chi 1=$ refers to independent factors of environments

$\beta 0=$ refers to as constant

$\varepsilon j \mathrm{j}=$ error term

Empirical Model denotes as

$y$ ip $=\sup \chi 1+$ cowker $\chi 1+$ com $\chi 1+$ wkcodi $\chi 1+$ slfiprve $\chi 1+$ rewd $\chi 1$

Where:

$y$ ip is employee job satisfactions and performance as dependent variable

$\sup \chi 1$ is supervision as independent variable

cowker $\chi 1$ is co-worker as independent variable

com $\chi 1$ is communication as independent variable

wkcodi is working condition as independent variable

slfiprv is self- improvement as independent variable

rewd $\chi 1$ is reward as independent variable

The basis for the use of the regression model is to assess whether one dependent variable (employee job satisfactions and performance) can be predicted from multiple independent variables from environment factors among others. The use of the regression model also strengthens the statistical nature of the analysis. It also helps in the replication of the research as other researchers may follow the method using the similar variables for further statistical analysis.

\section{Analysis of the study results}

This chapter presents the results of data collected from participants in the public service who were involved in the survey. In all, a total of 150 respondents were sampled for the survey. Table 1 shows the sex and age distribution level of the respondents 


\begin{tabular}{|c|c|c|c|}
\hline \multicolumn{2}{|c|}{ Variable } & Frequency & Percent \\
\hline \multirow{3}{*}{ Sex } & Male & 96 & $64.0 \%$ \\
\cline { 2 - 4 } & Female & 54 & $36.0 \%$ \\
\cline { 2 - 4 } & Total & 150 & $100.0 \%$ \\
\hline \multirow{3}{*}{ Age } & $20-30$ & 37 & $24.7 \%$ \\
\cline { 2 - 4 } & $31-40$ & 23 & $15.3 \%$ \\
\cline { 2 - 4 } & $41-50$ & 51 & $34.0 \%$ \\
\cline { 2 - 4 } & $51>$ & 39 & $26.0 \%$ \\
\cline { 2 - 4 } & Total & 150 & $100.0 \%$ \\
\hline
\end{tabular}

Table 1: Sex and Age of Respondents

Source: Field Survey, 2016

Majority of the respondents were males who accounted for $64 \%$ of the total sample size and the remaining $36 \%$ were females. The age distribution shows that respondents within the age group of 20-30 years were $24.7 \%$, 31-40 years were $15.3 \%$ while those more than 41 years were $60 \%$.

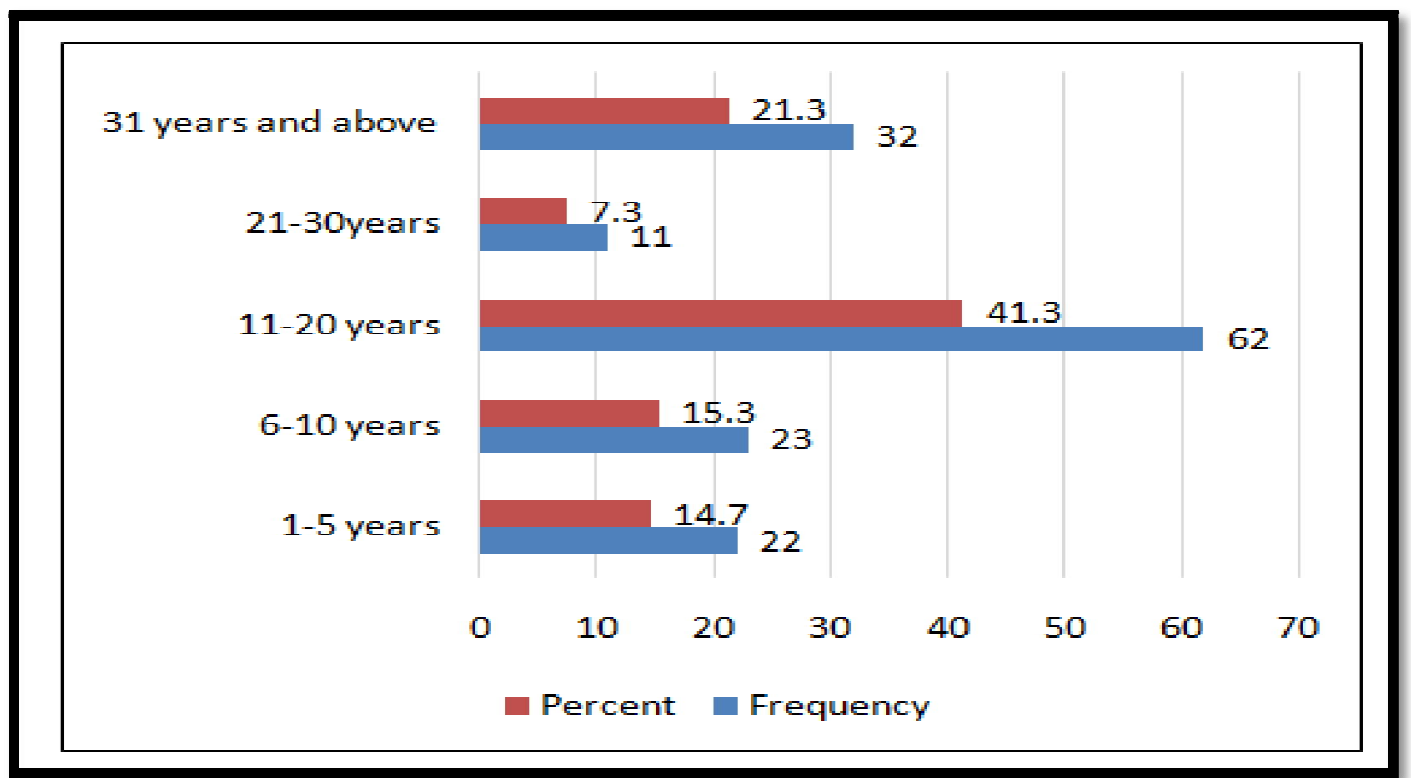

Figure 1: Work Experience

Figure 1 shows the work experience of the respondents in the survey. Respondents who had worked for 1-5 years were $14.7 \%$, 6 -10 years (15.3\%) and 11-20 years were $41.3 \%$. The remaining $28.6 \%$ had worked for more than 21 years in the public service.

\begin{tabular}{|c|c|c|c|}
\hline Statement & $\mathbf{N}$ & Mean & St. Dev. \\
\hline My job is important and it has an effect on other people. & 150 & 2.31 & 1.05 \\
\hline $\begin{array}{c}\text { My job allows me to complete a whole piece of work from } \\
\text { beginning to end and I can identify the results of my work }\end{array}$ & 150 & 2.87 & 0.86 \\
\hline My job requires me to do different tasks that use different skills & 150 & 3.34 & 0.61 \\
\hline I have the freedom to decide how to do my job. & 150 & 4.10 & 0.84 \\
\hline My job is difficult enough to challenge my skills and abilities. & 150 & 4.73 & 1.21 \\
\hline
\end{tabular}




\begin{tabular}{|c|c|c|c|}
\hline Statement & N & Mean & St. Dev. \\
\hline $\begin{array}{c}\text { My job provides the right amount of work for me to do, not too } \\
\text { much and not too little }\end{array}$ & 150 & 4.52 & 1.15 \\
\hline My job provides satisfactory working conditions. & 150 & 3.05 & 0.96 \\
\hline My job provides satisfactory pay. & 150 & 2.20 & 1.00 \\
\hline My hours of work are satisfactory. & 150 & 4.00 & 0.87 \\
\hline
\end{tabular}

\begin{tabular}{|c|c|c|c|}
\hline The amount of control and responsibility I am given. & 150 & 4.32 & 0.72 \\
\hline My relationship with other workers. & 150 & 4.05 & 1.03 \\
\hline The feedback I get from other workers and supervisors & 150 & 3.92 & 1.39 \\
\hline Theing able to tell how well I am performing whilst doing the job. & 150 & 3.87 & 1.22 \\
\hline $\begin{array}{c}\text { The amount of involvement I have in making decisions that affect } \\
\text { me. }\end{array}$ & 150 & 3.85 & 0.67 \\
\hline $\begin{array}{c}\text { The feeling that I am doing something important, something that } \\
\text { really matters }\end{array}$ & 150 & 3.88 & 1.22 \\
\hline
\end{tabular}

\begin{tabular}{|c|c|c|c|}
\hline Being able to complete a whole piece of work. & 150 & 3.33 & 0.61 \\
\hline Employees understand specific needs of supervisors and managers. & 150 & 3.13 & 1.07 \\
\hline $\begin{array}{l}\text { Employees are able to put themselves in the managers' place } \\
\text { (empathy). }\end{array}$ & 150 & 3.67 & 0.86 \\
\hline $\begin{array}{c}\text { Employees are able to "tune in" to each supervisor's needs or } \\
\text { requirements. }\end{array}$ & 150 & 3.85 & 0.67 \\
\hline Employees do more than usual for managers and supervisors. & 150 & 3.01 & 0.55 \\
\hline $\begin{array}{c}\text { I am told by my supervisor or other workers how well I am } \\
\text { performing. }\end{array}$ & 150 & 3.55 & 0.63 \\
\hline
\end{tabular}

Table 2: Descriptive Statistics of Environmental Sub-Factors

Source: Field Survey, 2016

Table 1 presents the descriptive statistics of the various items in the environment sub-factors used in the survey. As can be seen in Table 1, the statement with the highest mean value is "My job is difficult enough to challenge my skills and abilities" with mean value of 4.73. The statement with the second highest mean value is "My job provides the right amount of work for me to do, not too much and not too little" with mean value of 4.52. The statement with the third highest mean is "the amount of control and responsibility I am given" with mean value of 4.32. The statement that had the lowest mean is "My Job provides satisfactory pay" with a mean value of 2.20. The item with the lowest mean value is "The amount of variety in my job" with a mean value of 3.08. This is followed by "Employees are able to put themselves in the managers' place (empathy)" with a mean value of 3.67. The statement with the least mean value is "My job is important and it has an effect on other people" with a mean value of 2.31 .

\section{Regressions}

A linear regression test was performed to establish the relationship between the dependent variable (employee Job Satisfaction \& performance) and the independent variables as stated in the empirical model. 
Table 1 shows the results of the Ordinary Least Squares regression performed. The dependent variable for the regression is employee job satisfaction and performance while the independent variables include: working conditions, selfimprovement, reward, supervision, co-worker and communication

\begin{tabular}{|c|c|c|c|c|c|c|}
\hline & & $\begin{array}{c}\text { Unstandardized } \\
\text { Coefficients } \\
\end{array}$ & & $\begin{array}{c}\text { Standardized } \\
\text { Coefficients }\end{array}$ & & . \\
\hline \multicolumn{2}{|r|}{ Model } & B & Std. Error & Beta & T-test & P-value \\
\hline \multirow[t]{7}{*}{1} & (Constant) & 2.340 & 1.247 & & 1.863 & 0.062 \\
\hline & Reward & 0.561 & 0.143 & 0.765 & 3.909 & 0.001 \\
\hline & $\begin{array}{c}\text { Self- } \\
\text { improvement }\end{array}$ & -0.052 & 0.140 & -0.083 & -.357 & 0.703 \\
\hline & Supervision & -0.591 & 0.329 & -0.234 & -1.782 & 0.073 \\
\hline & Communication & 0.727 & 0.188 & 0.285 & 3.855 & 0.001 \\
\hline & Co-worker & -0.255 & 0.160 & -0.109 & -1.579 & 0.110 \\
\hline & $\begin{array}{c}\text { Working } \\
\text { conditions }\end{array}$ & 0.907 & 0.110 & 0.400 & 8.231 & 0.001 \\
\hline
\end{tabular}

Table 3: Regression Coefficients

Dependent Variable: Employee Job Satisfaction \&Performance

As shown in Table 1 above, reward had a positive correlation with employee job satisfaction and performance with coefficient of (0.765) and statistically significant at the $5 \%$ level of significance ( $p<0.05$ ). These results imply that an increase in employee rewards such as money, promotion,benefits, etc. of $5 \%$ will improve employee job satisfaction and performanceby $77 \%$, all things being equal.

Self-improvement, on the other hand, had a negative relationship with employee job satisfaction and performance with coefficient of $(-0.083)$ and statistically not significant at the $5 \%$ level of significance ( $p>0.703)$. This implies that given employees high level of training to acquire skills does not mean that she / he would be satisfied and apply it to translate to work performance.

Level of supervision had a negative relationship with employee job satisfaction and performance with coefficient of ($0.234)$ and statistically not significant at the $5 \%$ level of significance $(p>0.073)$. This implies that high level of supervision sometimes deters employees to increase their job performance. Most employees would like to work freely without supervisions.

Communication, on the other, had a positive relationship with employee performance with coefficient of $(0.282)$ and statistically significant at the $1 \%$ level of significance. This implies that a $1 \%$ improvement in communication will increase employee performance by $28 \%$, all things being equal.

The co-worker had a negative relationship with employee job satisfaction and performance with coefficient of ($0.109)$ and statistically not significant at the $5 \%$ level of significance $(p>0.110)$. Working conditions had a positive relationship with employee performance with coefficient of (0.400) and statistically significant at the $1 \%$ level of significance. This implies that a $1 \%$ increase in any components of working conditions will improve employee job satisfaction and performance by $40 \%$, all things being equal.

\section{Discussions of the Study Results}

The aim of this study was to empirically assess the effect of environment on employees'job satisfactions and performance in the public service in Ghana. The public sector in Ghana is an important as its objective is to implement government policies. The sector has also seen many agitations and strikes from workers as a result of the poor environment and low remunerations in the sector. This chapter is devoted to a discussion of the findings of the study.

The purpose of this study was to empirically examine the effect of working conditions, self- improvement, reward, co-worker, supervision and communication on employee performance in the public service.

In the regression analysis performed here, there was a positive correlation between working conditions and job performance with (Beta $=0.400, \mathrm{p}<0.05$ ). The result was also statistically significant within the $5 \%$ level of significance. This finding implies that within the public service, an improvement in working conditions of employees will lead to a corresponding increase in job performances of the employees. Working conditions of the employee is important if they are to be satisfied and work well. The study also found working conditions to be a predictor of job satisfaction and performances. Job conditions include the use of inputs required by the employee at the work place. This means that when the conditions of work are improved the employees will be satisfied and work well to increase output. 
This finding supports the study by Asharaf, Azam and Asharaf (2015) who's study shows that good wages, had positive impact on employees' performances levels. The findings also revealed that good wages, job security and good working conditions are the three top most important strategies in relation to employee performance. This study supports the study by Anupam and Mammoud (2014) who found that financial incentives impacted positively on employee job satisfaction and performance.

Relationship among coworkers is important in determining job performance of employees. There was a negative relationship between co- workers and job satisfaction and performance with (Beta $=-0.109, p>0.11$ ). This finding was also statistically not significant within the $5 \%$ level of significance. This implies that when there is an improvement in relationship among coworkers, this will lead to a corresponding decrease in job performance among employees. This may be due to lack of co-worker's concentration during working hours for the fact that they may engage in private discussions which may not benefitjob performances

Reward, on the other, had a positive relationship with employee performance with coefficient of (Beta $=0.77)$ and statistically significant at the $1 \%$ level of significance. This implies that a $1 \%$ improvement in reward such as money, benefits, and promotions will increase employee performance by $77 \%$, all things being equal. This study found a strong and positive relationship between reward and job satisfaction and performances. This finding corroborates earlier empirical studies Mafini and Dlodlo, (2014). According to Gerald and Dorothee (2013), rewards are very strongly correlated with job satisfaction. This means that employees are motivated to work when they are remunerated well. Lewis and Frank (2004) found a strong and positive correlation between remuneration and satisfaction

The self- improvement of the employee had a negative relationship with employee performance with coefficient of (Beta $=-0.083$ ) and statistically not significant at the $5 \%$ level of significance.

The regression results from the study shows that self-improvement is not a significant predictor of employee performance implying that employees may be satisfied in their training, skills but it may not necessarily translate into improved performance. Some studies have found job satisfaction as a positive predictor of employee performance (see Olcer, 2015).

The level of communication from supervisors is important in determining the job satisfaction and performances of employees. When supervisors relate well with their employees in a cordial manner, there is the possibility that employees will be happy and give-up their best. This finding from the multiple regressionshad a negative relationship between supervision and employees job satisfactions and performances.This finding does not corroborate the study by Mafini and Dlodlo (2014) who found a positive relationship between supervision and satisfaction.

The results of the study showed that communication is a positive predictor of job performance. This includes the type of task been undertaken, the tools available to communicate effectively and the work environment among others.

\section{Conclusions}

This study presents empirical data, in the results and discussion that has ensured, which shows the effect of employees' job satisfaction and performance. The regression results show a positive influence between reward, communication, working conditions on employees' job satisfaction and performance. However, there was negative influence between self- improvement, supervision, and co- workers on employees' job satisfaction and performance. These findings have contributed immensely in the field of HRM and several public-sectororganizations' where there has been the need to motivate employees with the view to improving productivity.

\section{Recommendation}

- Employers should be encouraged to pay critical attention on improving given more rewards to employees in order to enhance their productivity.

- Employers should endeavor to minimize employees' coworker communication especially during working hours so as to avoid repercussion on the level of output.

- 3Again, strict and stringent supervision should not be encouraged but supervisors should be flexible during supervision.

\section{References}

i. Anderfuhren-Biget, E. A. (2013). Motivating Employees of the Public Sector: Does Public Service Motivation Matter? a paper presented at IRSPM Conference, (p. 20). Bern.

ii. Anupam, D. (2014). Impact of Motivation Strategies on Employee Performance: A Comparative Study of Two Hotels in Canada and Saudi Arabia. Proceedings of 11th Asian Business Research Conference 26-27 December' 2014. Dhaka, Bangladesh: BIAM Foundation.

iii. Attrams, R. (2013). Motivation and Employee Satisfaction: Perceptions of Workers in Public and Private Health Care Facilities. . M.Phil. Thesis, University of Ghana, Legon.

iv. Brayfield, A. H. (1955). Employee attitudes and employee performance. Retrieved from http:/ / dx.doi.org/ 10.1037/ h0045899.

v. Bright, L. (2009). Why Do Public Employees Desire Intrinsic Nonmonetary Opportunities? In Public Personnel Management (Vol. 38, pp. 15-37). 
vi. Buelens, M.(2007). An Analysis of Differences in Work Motivation between Public and Private Sector Organizations, Vol. , , p.. Public Administration Review,,67, 65-74.

vii. Christensen, P. (2013). Motivational strategies for public managers: The budgetary belt-tightening precipitated by the recession has placed renewed emphasis on the importance of employee motivation, Government Finance Review: http. Retrieved from http:/ / findarticles.com/ p/articles/mi_hb6642/ is_2_18/ai_n28910543/ ?tag=content;col.

viii. Dunford, R. W. (2012). Organizational Behaviour: An Organizational Analysis Perspective. Addison-Wesley Business Series.

ix. Durant. (2012). Motivating employees in a new governance era: The performance paradigm.

x. Greenberg, P. (2012). Behaviour in Organization (8th ed.). Bloomsbury UK: Prentice-Hall. GILLHAM B (2013), Research Interview.

xi. Herzberg, F. ( 2003 ). One More Time: How Do You Motivate Employees?

xii. Jin, M. H. (2012). The Effects of Autonomy, Experience, and Person-Organization Fit on Job Satisfaction. The Case of Public Sector. The International Journal of Social Sciences, 6(1), 18-44.

xiii. Kaiser, C. L. (2014). Job Satisfaction and Public Service Motivation. . North Rhine-Westphalia University of Applied Sciences for Public Administration.

xiv. Landy, J., \& Conte, M. (2012). Work in the 21st Century: An introduction to industrial and organizational psychology (3rd ed.). McGraw Hill.

xv. Miner, J. B. (2012). Organizational Behavior 1: Essential Theories of Motivation and Leadership.

xvi. Mitchell, T. R. (2012). Motivation: New Directions for Theory, Research, and Practice. The Academy of Management Review, 7, pp. 80-88.

xvii. Paarlberg, E.A (2012). Theory to Practice: Strategies for Applying Public Service Motivation. In J. L. Perry (Ed.), Motivation in Public Management: the Call of Public Service (pp. 268-293). Oxford University Press.

xviii. Perry, J. \&. (2012). Motivation in Public Management: the Call of Public Service. Oxford University Press.

xix. Petrovsky, N. (2013). Public service motivation and performance: a critical perspective. Retrieved June 4th, 2016, from http:/ / www www.emeraldinsight.com/ 2049-3983.htm

xx. Rainey, H. G. (2012). Work Motivation, Handbook of Organizational Behavior. (R. Golembiewski, Ed.) Marcel Dekker.

xxi. Rainey, H. G. (2012). Work Motivation, Handbook of Organizational Behavior. (R. Golembiewski, Ed.) Marcel Dekker.

xxii. Robison, S. \&. (2013). Disengagement Can Be Really Depressing. Gallup Management Journal website. Retrieved 42 , 2010, from http:/ / gmj.gallup.com/ content/ 127100/ disengagement-really-depressing.aspx

xxiii. Schwartz, B. (2004). The Tyranny of Choice, Scientific American Magazine.

xxiv. Taylor, J. \&. (2011). “Working Hard for More Money or Working Hard To Make a Difference? . In Efficiency Wages, Public Service Motivation, and Effort." Review of Public Personnel Administration, (pp. 67-86,31(1)).

xxv. Van Loon, M. N. (2015). The Role of Public Service Motivation in Performance. Examining the potentials and pitfalls through an institutional approach. Unpublished PhD Dissertation.

xxvi. Van Wart, M. (2012). Leadership in Public Organizations: An Introduction, M.E. Sharpe.

xxvii. Vandenabeele, W. (2012). Toward a Public Administration Theory of Public Service (Vol. 9).

xxviii. Watson, T. J. (1986). Management, Organization, and Employment Strategy. New Directions in Theory and Practice.

xxix. Weibel, A. R. K., \& Osterloh, M. (2010). Pay for Performance in the Public Sector- Benefits and (Hidden) Cost (Vol. 20). Journal of Public Administration Research and Theory.

xxx. Wright, B. E. (2001). Public Sector Work Motivation: Review of Current Literature and a Revised Conceptual Model. Journal of Public Administration Research and Theory, 1, 556-586.

xxxi. Zikmund, W. (2007). Business Research Methods: .Essentials of Marketing Research. USA, Thompson South-Western 